\title{
Use of Anticoagulant Therapy in Patients with Acute Myocardial Infarction and Atrial Fibrillation
}

\author{
Ratko Lasica ${ }^{1, *}$, Lazar Djukanovic ${ }^{1}$, Dejana Popovic ${ }^{2}$, Lidija Savic ${ }^{1}$, Igor Mrdovic ${ }^{1}$, Nebojsa Radovanovic ${ }^{1}$, \\ Mina Radosavljevic Radovanovic ${ }^{2}$, Marija Polovina ${ }^{1}$, Radan Stojanovic ${ }^{3}$, Dragan Matic ${ }^{2}$, , Ana Uscumlic ${ }^{1}$ \\ and Milika Asanin ${ }^{1}$
}

Citation: Lasica, R.; Djukanovic, L.; Popovic, D.; Savic, L.; Mrdovic, I.;

Radovanovic, N.; Radovanovic, M.R.; Polovina, M.; Stojanovic, R.; Matic, D.; et al. Use of Anticoagulant Therapy in Patients with Acute Myocardial Infarction and Atrial Fibrillation. Medicina 2022, 58, 338. https://doi.org/10.3390/ medicina58030338

Academic Editors: Giuseppe Andò and Pierpaolo Di Micco

Received: 23 December 2021 Accepted: 12 February 2022 Published: 23 February 2022

Publisher's Note: MDPI stays neutral with regard to jurisdictional claims in published maps and institutional affiliations.

Copyright: (c) 2022 by the authors. Licensee MDPI, Basel, Switzerland. This article is an open access article distributed under the terms and conditions of the Creative Commons Attribution (CC BY) license (https:/ / creativecommons.org/licenses/by/ $4.0 /)$.
1 Department of Cardiology, Emergency Center-Clinical Center of Serbia, 11000 Belgrade, Serbia; lazardjukanovic08@gmail.com (L.D.); lidijasavic2007@gmail.com (L.S.); igormrd@gmail.com (I.M.); radovanovicn@sbb.rs (N.R.); marija_polovina@yahoo.com (M.P.); anauscumlic@gmail.com (A.U.); masanin2013@gmail.com (M.A.)

2 Department of Cardiology, Clinical Center of Serbia, 11000 Belgrade, Serbia; dejanapopovic@yahoo.co.uk (D.P.); mivasrce14@gmail.com (M.R.R.); dragan4m@gmail.com (D.M.)

3 Department of Pharmacology, Clinical Pharmacology and Toxicology, Faculty of Medicine, University of Belgrade, 11000 Belgrade, Serbia; radan@doctor.com

* Correspondence: drlasica@gmail.com

\begin{abstract}
The incidence of atrial fibrillation (AF) in acute coronary syndrome (ACS) ranges from 2.3-23\%. This difference in the incidence of AF is explained by the different ages of the patients in different studies and the different times of application of both reperfusion and drug therapies in acute myocardial infarction (AMI). About $6-8 \%$ of patients who underwent percutaneous intervention within AMI have an indication for oral anticoagulant therapy with vitamin $\mathrm{K}$ antagonists or new oral anticoagulants (NOAC).The use of oral anticoagulant therapy should be consistent with individual risk of bleeding as well as ischemic risk. Both HAS-BLED and CHA2DS2VASc scores are most commonly used for risk assessment. Except in patients with mechanical valves and antiphospholipid syndrome, NOACs have an advantage over vitamin K antagonists (VKAs). One of the advantages of NOACs is the use of fixed doses, where there is no need for successive INR controls, which increases the patient's compliance in taking these drugs. The use of triple therapy in ACS is indicated in the case of patients with AF, mechanical valves as well as venous thromboembolism. The results of the studies showed that when choosing a P2Y12 receptor blocker, less potent P2Y12 blockers such as Clopidogrel should be chosen, due to the lower risk of bleeding. It has been proven that the presence of AF within AMI is associated with a higher degree of reinfarction, more frequent stroke, high incidence of heart failure, and there is a correlation with an increased risk of sudden cardiac death. With the appearance of AF in ACS, its rapid conversion into sinus rhythm is necessary, and in the last resort, good control of heart rate in order to avoid the occurrence of adverse clinical events.
\end{abstract}

Keywords: acute myocardial infarction; atrial fibrillation; anticoagulant therapy

\section{Introduction}

Atrial fibrillation is an atrial tachyarrhythmia characterized by uncoordinated atrial depolarization, with impaired mechanical function and variable, irregular ventricular frequency. In the world, AF is the most common long-term cardiac arrhythmia in the adult population with an estimated prevalence of $2-4 \%$. An increase in AF in the future is predicted due to extended life expectancy as well as more intensive searches for asymptomatic $\mathrm{AF}$ in the population of patients at risk [1].

According to the World Health Organization, cardiovascular diseases are the leading cause of morbidity and mortality in the world, of which AMI is the most common. Acute coronary syndrome is the cause of more than 4 million deaths in Europe and Asia, as well as more than 2.4 million deaths in the United States each year. Although mortality from ACS 
is still high, it has been declining in recent decades, both due to lifestyle changes in primary prevention and the use of modern evidence-based therapy. ACS, which is accompanied by complications such as heart failure or the appearance of malignant arrhythmias, is associated with a worse prognosis. It is estimated that approximately $90 \%$ of patients with ACS have some of the arrhythmias in the first $24 \mathrm{~h}$ after the onset of the disease. The occurrence of AF during ACS is associated with a longer period of hospitalization, frequent complications and higher both in-hospital and overall mortality [2].

The incidence of AF in acute coronary syndrome, according to studies, ranges between $2.3-23 \%[1,3]$. This difference in the incidence of AF is explained by the different ages of the patients within different studies and the different times of application of both reperfusion and drug therapies in AMI. Randomized TRACE and OPTIMAAL studies examining the efficacy of drugs such as ACE inhibitors or ARBs in ACS have shown a lower incidence of AF in the ACS framework, which could be explained by the antiarrhythmic effect of these drugs $[4,5]$.

In addition to the fact that ACS poses a risk for AF, the REGARDS study showed that AF increases the risk of developing ACS more than 2 times, especially in the female population [6]. Similar results were shown by the ARIC study, although the association of AF with the occurrence of ACS has been demonstrated only for the subpopulation of patients who had AMI without ST-segment elevation (NSTEMI) [7]. The literature lists some of the mechanisms for the occurrence of AF within AMI: atrial ischemia, sinoatrial node ischemia, right ventricular ischemia, and left ventricular dysfunction, acute heart failure leading to atrial fibrillation and thus stimulating cardiomyocyte excitability, sympathetic dysfunction, endothelial dysfunction and systemic inflammation.

The effect of AF on AMI occurrence is explained by the induction of coronary thromboembolism, which accounts for approximately $3 \%$ of all AMI [8]. Another reason may be the reduced blood supply to the coronary blood vessels due to the tachyarrhythmic effect on the shortening of diastole. In addition, the influence of inflammation in both AMI and $\mathrm{AF}$ affects the development and progression of coronary heart disease.

\section{Association of Atrial Fibrillation and AMI}

Atrial fibrillation is one of the most common arrhythmias in patients with AMI. Among the first studies to examine the frequency and prognostic significance of AF within NSTEMI and ST-elevation myocardial infarction (STEMI) was the RICO study. This study did not show a significant difference in the frequency of AF between patients with AMI with or without ST elevation [9]. In this study, AF was shown to be an independent predictor of death in patients with NSTEMI. Similar results were presented in a retrospective cohort study performed on 6705 patients, of which 3094 patients had STEMI while 3611 had NSTEMI.

Atrial fibrillation was registered in $5.4 \%$ of patients, with the incidence of AF in patients with STEMI and NSTEMI being similar (5\% vs. $5.6 \%$, respectively); in $2.1 \%$ of patients AF was diagnosed earlier, while it was detected as new in $3.2 \%$ of patients [10]. Compared to previous studies that used a standard electrocardiogram to diagnose arrhythmias in patients with AMI, the CHARISMA study was among the first studies to use continuous heart rate monitoring to detect arrhythmias within AMI in patients with reduced ejection fraction $(\mathrm{EF})$.

In this study, the incidence of newly developed $\mathrm{AF}$ was estimated at $28 \%$ over a 1.9-year follow-up period [11]. Analysis of AREST study data concluded that the cumulative incidence of AF after AMI in patients with preserved $\mathrm{EF}$ is quite underestimated due to numerous asymptomatic cases (approximately $90 \%$ ) and the inability to detect them without a continuous electrocardiogram. This study showed that more than $60 \%$ of patients after AMI have newly developed AF in the 24-month follow-up period, with the highest incidence between 3 and 6 months of follow-up [12].

The discrepancy between the AF frequencies within these two studies can be explained by the earlier start of rhythm monitoring within the AREST study as well as by the ap- 
plication of a more accurate algorithm for AF detection. Recent studies (SCREEN-AF and The LOOP study) that examined, among other primary goals, the incidence of AF in the general population independent of ACS found that the use of continuous monitoring to detect arrhythmias greatly increased the detection of asymptomatic cases of AF. The importance of paroxysms of asymptomatic AF as well as the need for their treatment is still debatable $[13,14]$.

\section{Association of ACS Treatment with the Incidence of AF}

The use of drug reperfusion therapy (thrombolytic therapy) in AMI has reduced both mortality and the incidence of major adverse cardiac events (MACE). Nielsen et al. showed in a small number of patients a decrease in the incidence of AF in patients who received thrombolytic therapy compared to those treated conservatively [15]. Eldar et al. confirmed this opinion by comparing patients who received thrombolytic therapy $(46.3 \%)$ to those who did not receive thrombolytic therapy. A significantly lower incidence of paroxysmal $\mathrm{AF}$ was registered in patients treated with thrombolytic therapy (6.7\% vs. $10.8 \%$ ).

Additionally, in his study, comparing the occurrence of AF in the period before thrombolytic therapy with the period of thrombolytic therapy, a similar incidence of paroxysmal AF was observed (9.9\% vs. $8.9 \%)$. Patients with AF in the thrombolytic era have been shown to be older, with a higher incidence of comorbidities compared with patients in the prethrombolytic era [16].

Between 1990 and 1997, Goldberg et al. published a study showing a decline in the incidence of $\mathrm{AF}$ from $18 \%$ to $11 \%$ in patients after $\mathrm{AMI}$ [17]. An incidence of $\mathrm{AF}$ of $10.4 \%$ was registered in the GUSTO I study among patients with AMI treated with fibrinolytic therapy [18]. Among the first studies to assess the incidence of AF in patients with acute coronary syndrome who underwent PCI within $24 \mathrm{~h}$ of symptoms onset, one showed an incidence of $\mathrm{AF}$ of $12 \%$, with $4.3 \%$ of patients having $\mathrm{AF}$ on admission and $7.7 \%$ developing AF during hospitalization [19]. Moreover, Podolecki et al. published a study conducted in the period from 2003 to 2008, which included 2980 patients with AMI who were treated with an invasive approach. Atrial fibrillation was registered in $9.5 \%$ of patients [20].

\section{Presence of Risk Factors for AF in AMI}

Atrial fibrillation is a common arrhythmia in patients with ACS, and its occurrence is more frequent if risk factors are present (Figure 1).

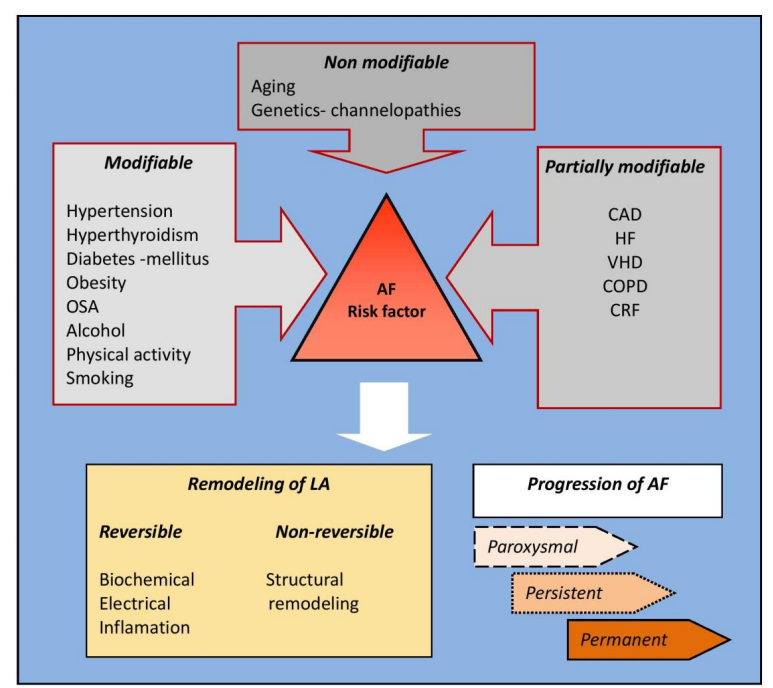

Figure 1. Cardiovascular risk factors for the development of $\mathrm{AF}$ [1]: Legend: $\mathrm{AF}$-atrial fibrillation; CAD—coronary artery disease; COPD—chronic obstructive pulmonary disease; LA—left antrum; OSA— obstructive sleep apnea; HF—heart failure; VHD—valvular heart disease; CRF—chronic renal failure. 


\section{AF Predictors in AMI}

Previous studies have shown that changes in the values of some laboratory parameters, pathological findings of echocardiography and the occurrence of heart failure during AMI may be associated with the occurrence of AF.

\subsection{Laboratory Parameters}

Within ACS, the most frequently examined predictors of AF were $\mathrm{N}$-terminal prohormone of brain natriuretic peptide (NT-pro BNP), C reactive protein (CRP) and Troponin, which are routinely used as diagnostic and prognostic laboratory parameters in patients with ACS. According to the TRIUMPH registry, independent predictors of AF development in AMI were NT-pro BNP as well as CRP [21]. A Dorje et al. study conducted in the period from January 2008 to December 2011 included 268 patients with AMI. New AF was registered in $13.4 \%$ of respondents.

After multivariate analysis, the B-type NP value $\geq 796 \mathrm{pg} / \mathrm{mL}$ was an independent predictor of newly developed AF in these patients (OR 5.1, 95\% CI 1.7-15.5, $p=0.004$ ) [22] Asanin et al., in a study of patients with STEMI treated with primary PCI, showed that patients with elevated B-type natriuretic protein $24 \mathrm{~h}$ after the onset of symptoms had a higher incidence of AF than the control group [23]. The predictive values of BNP for the occurrence of $\mathrm{AF}$ is proven in the general population although not in all studies [24,25]. As recent research supports the association of systemic inflammation with the development and maintenance of AF, as well as the importance of the inflammatory response to tissue damage within AMI, the predictive value of CRP as an independent indicator of systemic inflammation was considered.

In a study by Aronson et al. that included patients with AMI, after a multivariate analysis CRP proved to be an independent predictor of this arrhythmia [26]. Finally, Troponin T biomarker specific for myocardial damage has not been shown, in both the TRIUMPH study and other studies, to be an independent predictor of AF development within AMI [23]. The results of Gal et al. showed an association between hsTnT values measured at different intervals and newly developed AF between 24-72 $\mathrm{h}$ as well as $72 \mathrm{~h}$ after hospital admission [27]. Such data are also supported by a recent study by Raczkowska-Golanko et al. [28].

It should always be borne in mind that elevated levels of Troponin may be associated with a variety of cardiac and non-cardiac conditions. Cardiac conditions with increased Troponin values are: acute and chronic heart failure, acute myocarditis, arrhythmias and aortic dissections, while non-cardiac conditions are pulmonary embolism, sepsis, stroke and many others $[29,30]$. Troponin levels are also elevated in patients with renal insufficiency and during strenuous exercise [31,32].

\subsection{Echocardiographic Parameters}

It has long been known that the likelihood of developing AF within the general population increases with increasing left atrial diameter as well as decreasing left ventricular ejection fraction (LVEF) [33]. According to a meta-analysis that included ten studies with patients with newly diagnosed AF, decreased LVEF as well as increased left atrial diameter were associated with a higher risk of AF after AMI [34]. In addition, according to a study by Raczkowska-Golanko et al., left atrial diameter $\geq 41 \mathrm{~mm}$ and $\mathrm{LVEF} \leq 44 \%$ were significant predictors of newly developed AF in univariate analysis in patients with AMI. EF has also been shown to be significant in multivariate analysis [28].

\subsection{Heart Failure in AMI as a Predictor of AF Development}

Heart failure is the most significant predictor of AF development in patients with AMI. In a study by Asanin et al., heart failure within the AMI was examined as an independent predictor of AF. New AF was classified as early if it occurred within $24 \mathrm{~h}$ of the onset of heart failure symptoms and late if it occurred after this period. Heart failure according to multivariate analysis was the most important predictor of AF (OR 3.03, 95\% CI, 2.08-4.43, 
$p<0.0001$ ) [35]. Moreover, in patients with AMI, the presence of advanced diastolic dysfunction was independently associated with new-onset AF [36,37].

\section{Influence of AF on Clinical Outcome within AMI}

Atrial fibrillation is associated with significant morbidity and mortality, and poses a significant burden to patients, public health and the health economy. According to the ESC Guidelines for 2021, AF is independently associated with twice the mortality in the female population and 1.5 times the mortality in the male population [1]. The GUSTO I study showed that newly developed AF was an independent predictor of both 30-day and 1-year mortality in patients with ACS. Patients who develop AF during hospitalization are more likely to have heart failure, reinfarction and asystole [18]. In the GISSI-3 study, which included patients with ACS, it was shown that in the group of patients who developed $\mathrm{AF}$, the intrahospital mortality was $12.6 \%$, while in the group without this arrhythmia it was $5 \%$.

AF was a predictor of both in-hospital and late mortality in this study [38]. Rathore et al. showed, in a meta-analysis of 106780 elderly patients after AMI, that patients with AF had higher mortality rates compared to those without AF-intrahospital ( $23.3 \%$ vs. $16.0 \%$ ); 3 -day $(29.3 \%$ vs. $19.1 \%)$ and 1-year ( $48.3 \%$ vs. $32.7 \%$ ) [39]. Jabre et al. also published a meta-analysis that included 43 studies between 1970 and 2010 and concluded that AF is an independent predictor of mortality in ACS when other negative prognostic factors are excluded [40].

A retrospective cohort study involving 6705 patients with STEMI and NSTEMI showed that emerging AF in NSTEMI patients was an independent predictor of 30-day mortality while this was not the case for patients with STEMI. In both patient sub-populations, AF was associated with increased intrahospital complications [10]. Lopes et al. showed in their study the association of AF with both early and late mortality and in sub-populations of STEMI and NSTEMI patients [41]. In contrast to these studies, a study of 2475 patients with ACS by Kinjo et al. with emerging AF did not prove to be an independent predictor of intrahospital mortality, but was associated with an increased risk of intrahospital complications [19].

A recent multicenter retrospective cohort study examined STEMI patients from the proACSregistry (Portuguese Registry on Acute Coronary Syndromes) from 2010 and 2017. Patients who developed AF compared to those with sinus rhythm had more frequent intrahospital complications: higher prevalence of SI, cardiogenic shock, AV block, ventricular tachycardia, cardiac arrest, mechanical complications, stroke, and major bleeding, but AF was not shown as an independent predictor of mortality within STEMI [42].

Patients with AF have an increased risk of thromboembolic complications, especially ischemic stroke. The risk of ischemic stroke in patients with AF, according to ESC Guidelines, is estimated at about 5 times higher than in the general population, and the risk in these patients is not homogeneous but varies compared to many other factors. Common risk factors for ischemic stroke are summarized within the CHA2DS2-VASc score [1]. The GUSTO-I study registered a significantly higher incidence of ischemic stroke during the hospital treatment period of patients with newly developed AF and ACS compared to patients without this arrhythmia $(3.1 \%$ vs. $1.3 \%, p<0.01)$ [18].

In addition, the OPTIMAAL study showed that the newly developed AF had an independent predictive value for the development of ischemic stroke both in the first 30 days and in the follow-up period of $2.7 \pm 0.9$ years [5].

The controversial question remains whether the long-term clinical impact on the risk of unwanted clinical events of newly diagnosed AF in the acute phase of AMI differs from the impact of previously diagnosed AF before the onset of AMI. The results of the Obayashi Y study (6228 patients with AMI treated with percutaneous intervention, 7.9\% with newly diagnosed $\mathrm{AF}, 9.5 \%$ with previously diagnosed $\mathrm{AF}$ and $82.7 \%$ without $\mathrm{AF}$ ) showed that patients with newly diagnosed AF in AMI had a higher risk of mortality than those hospitalized due to heart failure and major bleeding compared with patients 
without AF and comparable risk as patients with previous AF. The risk of stroke was far higher in patients with newly diagnosed AF than in those with previously diagnosed AF [43]. This study may reinforce the concept that consideration of anticoagulant therapy is mandatory in patients with newly diagnosed AF in AMI who have a high risk of stroke (CHA2DS2-VASc score $\geq 2$ ) even though the risk of bleeding is high.

\section{Prevention of Thromboembolic Complications in AMI Complicated AF}

About $6-8 \%$ of patients undergoing PCI have an indication for oral anticoagulant therapy with VKAs or NOACs [44]. The use of triple therapy in ACS is indicated in the case of patients with AF, mechanical valvulae and venous thromboembolism. The use of oral anticoagulant therapy should be consistent with individual risk of bleeding as well as ischemic risk. Both HAS-BLED and CHA2DS2VASc scores are most commonly used for risk assessment. When choosing VKAs or NOACs, it is important to determine if there is an associated valvular heart disease. In all patients with artificial heart valvulae as well as in patients with moderate or significant mitral stenosis, oral anticoagulant therapy is indicated regardless of other cardioembolic risk factors, and only VKAs drugs are recommended.

In all other patients with AF and one or more associated CHA2DS2VASc thromboembolic risk factors, the use of oral anticoagulant drugs is indicated, and NOACs are preferred. Compared with control or placebo, VKAs therapy reduces the risk of ischemic stroke by $64 \%$ and mortality by $24 \%$ [1]. Their use is limited by a narrow therapeutic interval, which requires frequent monitoring of the international normalized ratio (INR) and frequent dose adjustments. For optimal thromboprophylaxis, it is necessary that the TTR (time in therapeutic range) be $>70 \%$ [45]. In a comparison of efficiency in the prevention of thromboembolic complications, NOACs have been shown to be as efficient as VKAs [46-49].

These results were supported also by a meta-analysis showing that the use of NOACs reduces the risk of ischemic stroke and systemic embolism by $19 \%$ compared to the use of VKAs [50]. NOACs have been shown to be safer in relation to the risk of hemorrhagic stroke and other intracranial hemorrhages [1]. In the AUGUSTUS study, major or clinically relevant non-major bleeding was reported in $10.5 \%$ of patients receiving apixaban, compared with $14.7 \%$ of patients receiving VKA [51].

The lower mortality and the incidence of hospitalizations was in the group receiving apixaban compared to the group receiving VKA (23.5\% vs. $27.4 \%)$, while the incidence of ischemic complications was similar.

Comparing the efficiency and occurrence of complications during dual antiplatelet therapy (NOAK + P2Y12 inhibitor) and triple antiplatelet therapy (VKA + P2Y12 inhibitor + Aspirin), results of PIONER AF-PCI studies with rivaroxaban, a RE-DUAL PCI study with dabigatran, AUGUSTUS with apixaban, and ENTRUST-AF PCI with edoxaban were very similar. Significant reductions in major or clinically significant bleeding have been registered in patients receiving NOAK + P2Y12 inhibitor therapy. Approximate rates of ischemic stroke and a neutral effect on clinically defined major adverse cardiovascular events and all causes of mortality were reported, comparing dual (NOAK + P2Y12 inhibitor) and triple therapy (VKA + P2Y12 inhibitor + Aspirin), (Table 1) [51-54].

In addition, the advantage of NOACs over VKAs is in the use of fixed doses, where there is no need for successive controls of INR, which increases the patient's compliance in taking these drugs. When choosing a P2Y12 receptor blocker, the use of prasugrel or ticagrelor was associated with a higher risk of major bleeding compared to clopidogrel, and their use should be avoided in patients with ACS and AF [55,56]. Andreou et al. showed that the use of ticagrelor in double or triple antithrombotic therapy is associated with higher rates of clinically significant hemorrhagic complications compared to clopidogrel.

Moreover, the use of ticagrelor compared to clopidogrel in triple antithrombotic therapy has been associated with a higher incidence of MACE, while this was not the case when ticagrelor was used as part of dual antithrombotic therapy [56]. Dual antithrombotic therapy including OAC and P2Y12 receptor inhibitor has been associated with two to three times lower bleeding rates than triple therapy. However, available evidence suggests that 
shorter triple antiplatelet therapy is desirable to reduce thromboembolic complications in the first days after AMI [1].

Table 1. Main characteristics and results of the PIONER AF-PCI, RE-DUAL PCI, AUGUSTUS and ENTRUST-AF PCI trials [1,51-54].

\begin{tabular}{|c|c|c|c|c|c|c|c|c|c|}
\hline $\begin{array}{l}\text { Clinical } \\
\text { Trial }\end{array}$ & $\begin{array}{c}\text { Year of } \\
\text { Publication }\end{array}$ & $\begin{array}{l}\text { Cohort } \\
\text { Size }(n)\end{array}$ & $\underset{\text { PCI }}{\text { Primary }}$ & $\begin{array}{c}\text { Randomization } \\
\text { Window after } \\
\text { Index Event }\end{array}$ & $\begin{array}{c}\text { TAT Regimen } \\
\text { Duration } \\
\text { (Months) } \\
\end{array}$ & $\begin{array}{l}\text { Follow Up } \\
\text { (Months) }\end{array}$ & $\begin{array}{l}\text { Treatment } \\
\text { Strategy }\end{array}$ & $\begin{array}{l}\text { Safety Endpoint } \\
\text { Major or CRNM } \\
\text { ISTH Bleeding }\end{array}$ & MACE * \\
\hline \multirow{3}{*}{$\begin{array}{l}\text { PIONEER } \\
\text { AF-PCI } \\
\text { [52] }\end{array}$} & \multirow{3}{*}{2016} & \multirow{3}{*}{2124} & \multirow{3}{*}{$38.5 \%$} & \multirow{3}{*}{$72 \mathrm{~h}$} & \multirow{3}{*}{1,6 or12 } & \multirow{3}{*}{12} & $\begin{array}{c}\text { Rivaroxaban } \\
15 \mathrm{mg}+\mathrm{P} 2 \mathrm{Y} 12\end{array}$ & $16.8 \%$ & $6.5 \%$ \\
\hline & & & & & & & $\begin{array}{c}\text { Rivaroxaban } 2.5 \\
\text { mg bid + P2Y12 } \\
\text { aspirin }\end{array}$ & $18 \%$ & $5.6 \%$ \\
\hline & & & & & & & $\begin{array}{l}\mathrm{VKA}+\mathrm{P} 2 \mathrm{Y} 12+ \\
\text { aspirin }\end{array}$ & $26.7 \%$ & $6 \%$ \\
\hline \multirow{3}{*}{$\begin{array}{c}\text { RE- } \\
\text { DUAL } \\
\text { PCI } \\
{[53]}\end{array}$} & \multirow{3}{*}{2017} & \multirow{3}{*}{2725} & \multirow{3}{*}{$50.5 \%$} & \multirow{3}{*}{$120 \mathrm{~h}$} & \multirow{3}{*}{$\begin{array}{c}1 \text { (BMS) or } 3 \\
\text { (DES) }\end{array}$} & \multirow{3}{*}{14} & $\begin{array}{c}\text { Dabigatran } 110 \mathrm{mg} \\
\text { bid }+\mathrm{P} 2 \mathrm{Y} 12\end{array}$ & $15.4 \%$ & $15.2 \%$ \\
\hline & & & & & & & $\begin{array}{c}\text { Dabigatran } 150 \mathrm{mg} \\
\text { bid + P2Y12 }\end{array}$ & $20.2 \%$ & $11.8 \%$ \\
\hline & & & & & & & $\begin{array}{c}\mathrm{VKA}+\mathrm{P} 2 \mathrm{Y} 12+ \\
\text { aspirin }\end{array}$ & $26.9 \%$ & $13.4 \%$ \\
\hline \multirow{4}{*}{$\begin{array}{l}\text { AUGUSTUS } \\
{[51]}\end{array}$} & \multirow{4}{*}{2019} & \multirow{4}{*}{4614} & \multirow{4}{*}{$37.3 \%$} & \multirow{4}{*}{14 days } & \multirow{4}{*}{6} & \multirow{4}{*}{6} & $\begin{array}{c}\text { Apixaban } 5 \mathrm{mg} \\
\text { bid+ P2Y12 + } \\
\text { aspirin }\end{array}$ & $10.5 \%$ & $6.7 \%$ \\
\hline & & & & & & & $\begin{array}{c}\text { Apixaban } 5 \mathrm{mg} \text { bid } \\
+\mathrm{P} 2 \mathrm{Y} 12\end{array}$ & & \\
\hline & & & & & & & $\begin{array}{c}\mathrm{VKA}+\mathrm{P} 2 \mathrm{Y} 12+ \\
\text { aspirin }\end{array}$ & $14.7 \%$ & $7.1 \%$ \\
\hline & & & & & & & $\mathrm{VKA}+\mathrm{P} 2 \mathrm{Y} 12$ & & \\
\hline \multirow{2}{*}{$\begin{array}{l}\text { ENTRUST- } \\
\text { AF PCI } \\
\text { [54] }\end{array}$} & \multirow{2}{*}{2019} & \multirow{2}{*}{1506} & \multirow{2}{*}{$52 \%$} & \multirow{2}{*}{5 days } & \multirow{2}{*}{$1-12$} & \multirow[b]{2}{*}{12} & $\begin{array}{l}\text { Edoxaban }(60 \mathrm{mg}) \\
+ \text { P2Y12 }\end{array}$ & $17 \%$ & $7 \%$ \\
\hline & & & & & & & $\underset{\text { aspirin }}{\mathrm{VKA}+\mathrm{P} 2 \mathrm{Y} 12+}$ & $20.1 \%$ & $6 \%$ \\
\hline
\end{tabular}

Legend: $\mathrm{BMS}$ = bare-metal stent; $\mathrm{CRNM}=$ clinically relevant non-major; DES = drug-eluting stent; ISTH = International Society on Thrombosis and Haemostasis; PCI = percutaneous coronary intervention; TAT = triple antithrombotic therapy; $\mathrm{VKA}=$ vitamin $\mathrm{K}$ antagonist; $\mathrm{MACE} *$ major adverse cardiac event.

According to the guiding recommendations, in case of acceptable hemorrhagic risk, triple therapy of NOACs with P2Y12 inhibitor as well as aspirin is recommended for the first week to one month, and after that it is necessary to continue NOACs with P2Y12 inhibitor until the expiration of 12 months since ACS, after which only NOACs are left in therapy.

In patients with markedly increased ischemic risk, the duration of triple therapy should be extended to 3-6 months, while in cases of markedly increased hemorrhagic risk, dual therapy in combination with NOACs and P2Y12 inhibitor may be used from the outset. If there are no new ischemic events within 12 months of ACS/PCI, in the further course monotherapy with NOAC should be applied. Combining OAC therapy with P2Y12 receptor inhibitors such as ticagrelor and prasugrel is not currently recommended due to the increased risk of bleeding [57] (Figure 2).

Many studies have confirmed the positive effect of statins in the secondary prevention of ischemic stroke. The results of a study by Wankowicz et al. analyzed the effect of statin therapy before ischemic stroke on AF-related ischemic stroke in patients with well-controlled ventricular rate [58]. This retrospective multicenter analysis included 2309 patients with acute ischemic stroke. The results of the study showed that patients who used statins prehospitally had significantly lower neurological deficits compared with patients with stroke and AF who had not used statins before. Intrahospital mortality was also significantly higher in patients with atrial fibrillation-related stroke who did not take statins before hospitalization than in those who did. The results of this study suggest that the addition of statins to oral anticoagulants may be of great help in preventing stroke associated with atrial fibrillation, which must be confirmed by well-designed randomized, controlled studies. 


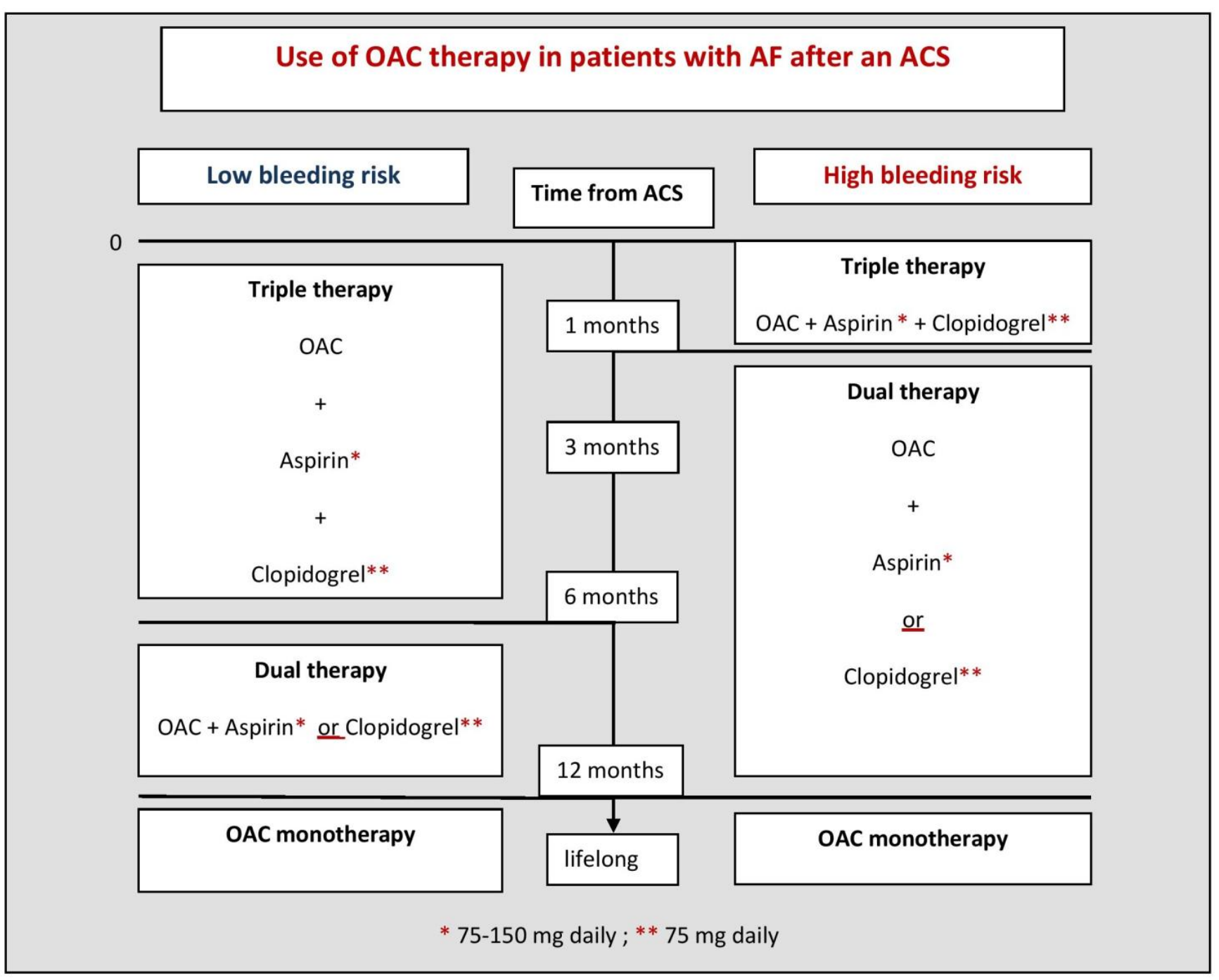

Figure 2. Use of OAC therapy in patients with AF after an ACS [57]. Legend: * Aspirin dose 75-150 mg daily; ** Clopidogrel dose $75 \mathrm{mg}$ daily; ACS-acute coronary syndrome; AF-atrial fibrillation; OAC - oral anticoagulation (using vitamin $\mathrm{K}$ antagonist or non-vitamin $\mathrm{K}$ antagonist oral anticoagulants).

\section{Treatment of Patients with AF within AMI}

The presence of AF within AMI has been shown to be associated with a higher rate of reinfarction, more frequent ischemic strokes, a higher incidence of heart failure, and a correlation with an increased risk of sudden cardiac death [59]. Therefore, adequate control of frequency, rhythm and the application of adequate prophylactic anticoagulant therapy is necessary. The RACE II study, conducted on the general population with AF, did not show that heart-rate control improves the quality of life or outcome in these patients [60]. In AMI, poor control of the rate of ventricular response during AF can worsen the symptoms of myocardial ischemia and precipitate heart failure worsening because any increase in frequency shortens the diastolic phase of the cardiac cycle and thus compromises perfusion through coronary blood vessels [1].

Danish researchers in the DIAMOND study showed that heart frequency is an independent prognostic factor for ten-year mortality in patients with AMI regardless of the presence of AF [61]. In acute conditions such as AMI, the associated factors that may affect the increase in frequency, such as anemia, infection, hypotension and hyperthyroidism, etc., should always be considered. In persons who do not have clinical symptoms and signs of heart failure as well as hypotension in AMI, intravenous beta-blockers are indicated for 
frequency control. Normotensive patients with extensive left ventricular damage and heart failure during AMI should receive amiodarone for heart frequency control, and digitalis may also be used in hypotensive patients [59].

Combined drug therapy may also be considered if monotherapy does not achieve the desired frequency. When using the combination of amiodarone and digoxin, it is necessary to monitor the concentration of digoxin in the blood due to the possible toxic effects of this drug. In the case of AF with a slow ventricular response, atropine may be used in hemodynamically stable patients, while in the case of symptomatic bradyarrhythmia, the option of choice is either emergency cardioversion or temporary pacemaker implantation [62]. Rhythm control in AF refers to attempts to establish and maintain sinus rhythm and in addition to the drug approach may include electrical cardioversion as well as catheter ablation.

The use of propafenone, vernakalant and flecainide is not recommended in patients with known coronary artery disease [1]. In the case of hemodynamic instability in patients with $\mathrm{AF}$, urgent electrical cardioversion is necessary. Administration of amiodarone prior to electroconversion has been shown to improve the likelihood of sinus rhythm conversion in patients with AF [63]. In addition, a study by Schmidt et al. showed that the application of a maximum energy of $360 \mathrm{~J}$ is more effective in cardioversion of AF to sinus rhythm compared to a successively increased energy dose (125 J-150 J-360 J) [64].

During electrical cardioversion, it is necessary to sedate the patient, the use of benzodiazepines (midazolam or diazepam) is recommended, and the use of propofol is also possible [65]. During the procedure, it is necessary to monitor the patient's blood pressure and saturation with pulse oximetry.

\section{Risk Assessment and Prevention of Hemorrhagic Complications in Patients with AF and AMI}

Provision of dual (i.e., an anticoagulant drug and one antiplatelet agent) or triple (i.e., an anticoagulant drug and two antiplatelet agents) antithrombotic therapy in patients with AF and AMI undergoing PCI procedure is associated with increased risk of hemorrhagic complications, especially in vulnerable individuals. These include patients of advanced age, severe renal or hepatic dysfunction, cancer, cognitive impairment or recent bleeding episode. Current guidelines recommend the assessment of bleeding risk with the use of a validated risk score, the HAS-BLED score before commencing the anticoagulant therapy [1]. Individuals identified to have a HAS-BLED score of three and above are considered to have high bleeding risk $(>10 \%$ per year) and merit careful attention when deciding on the type of anticoagulant drug, the combination of antiplatelet agents and the duration of dual or triple antithrombotic therapy. Firstly, all modifiable bleeding risk factors (e.g., uncontrolled hypertension, labile INR, frequent use of non-steroidal anti-inflammatory drugs or alcohol abuse) should be addressed. In that respect, the use of NOACs instead of VKAs has been shown to reduce bleeding events (in particular, intracranial hemorrhage) and obviate hazards associated with labile INR. Secondly, the duration of triple therapy should be kept at minimum, balancing the risk of potential stent thrombosis against the risk of bleeding [66,67]. Available evidence suggests that the minimum duration of triple therapy should last seven days after stent implantation, and thereafter, individuals at high bleeding risk and low risk of stent thrombosis can safely continue with dual antithrombotic therapy, which confers a significantly lower risk of bleeding. In individuals at high risk of stent thrombosis (i.e., multivessel PCI, complex revascularization of left main coronary artery, coronary bifurcations, a history of stent thrombosis, diabetesand chronic kidney disease, etc.), the optimal duration of triple therapy should be a shared decision between the interventional cardiologist and the treating physician.

Bleeding risk is often dynamic and may increase in time due to the occurrence or worsening of concomitant illnesses (i.e., renal or hepatic dysfunction, stroke, bleeding) or introduction of new drugs. Therefore, attention should be given to the changes in the bleeding risk profile, in particular in vulnerable patients, since these changes strongly 
correlate with the escalating risk of hemorrhagic complications [68]. A randomized study has demonstrated that dynamic monitoring and reassessment using the HAS-BLED score in conjunction with the mitigation of modifiable risk factors were associated with a lower risk of major bleeding events compared to the usual care [69].

\section{Conclusions}

Despite the fact that modern methods of treating acute coronary syndrome (application of thrombolytic therapy and primary percutaneous intervention with stent implantation in infarcted arteries) provide rapid recanalization of infarcted blood vessel and thus less frequent arrhythmias, it is concluded that the incidence of atrial fibrillation is still high.

Adequate treatment of hypertension and diabetes is necessary in order to reduce the occurrence of atrial fibrillation. Given that different degrees of renal impairment, from albuminuria to severe renal failure, are associated with a higher incidence of AF, adequate rehydration of patients with acute coronary syndrome is necessary to prevent prerenal renal failure and reduce the incidence of contrast-induced nephropathy.

The occurrence of AF with rapid ventricular rhythm is associated with more frequent complications: development of heart failure, extension of infarction and increased risk of sudden cardiac death, and the use of anticoagulant therapy during hospitalization and later indefinitely is necessary, which reduces the risk of ischemic stroke and systemic embolization. However, since the use of triple and then dual antiplatelet therapy is associated with a risk of bleeding, frequent re-evaluation of the risk of both ischemia and bleeding is necessary.

In particular, risk/benefit assessment (risk scores) should be performed in patients taking VKAs due to variations in INR values. The use of NOACs has facilitated the treatment of patients with AF and ACS, and they are recommended as a treatment option, especially in patients who have no contraindications to their use. A lower rate of bleeding has also been reported when co-administered with P2Y12 inhibitors, in particular clopidogrel. The use of NOACs with more potent P2Y12 inhibitors (ticagrelor and prasugrel) should be avoided due to the risk of bleeding.

\section{Potential Studies Limitations}

Most of the studies cited in this paper diagnosed AF on the basis of electrocardiograms and not on the basis of Holter electrocardiograms/continuous rhythm monitoring, which is why short-term AF (paroxysmal AF) could have been neglected. In addition, the occurrence of newly diagnosed AF in AMI might not have been registered.

Author Contributions: Conceptualization, methodology, investigation, data curation, writing, original draft preparation, R.L. and L.D.; original draft preparation, D.P., L.S., M.P. and A.U.; visuelization, I.M.; investigation, N.R., M.R.R., R.S. and D.M.; supervision, M.A. All authors have read and agreed to the published version of the manuscript.

Funding: This research received no external funding.

Institutional Review Board Statement: Not applicable.

Informed Consent Statement: Not applicable.

Data Availability Statement: Not applicable.

Conflicts of Interest: The authors declare that there is no conflict of interest. 


\section{References}

1. Hindricks, G.; Potpara, T.; Dagres, N.; Arbelo, E.; Bax, J.J.; Blomström-Lundqvist, C.; Boriani, G.; Castella, M.; Dan, G.-A.; Dilaveris, P.E.; et al. 2020 ESC Guidelines for the diagnosis and management of atrial fibrillation developed in collaboration with the European Association for Cardio-Thoracic Surgery (EACTS): The Task Force for the diagnosis and management of atrial fibrillation of the European Society of Cardiology (ESC) Developed with the special contribution of the European Heart Rhythm Association (EHRA) of the ESC. Eur. Heart J. 2021, 42, 373-498. [CrossRef] [PubMed]

2. Erez, A.; Goldenberg, I.; Sabbag, A.; Nof, E.; Zahger, D.; Atar, S.; Pollak, A.; Dobrecky-Merye, I.; Beigel, R.; Matetzky, S.; et al. Temporal trends and outcomes associated with atrial fibrillation observed during acute coronary syndrome: Real-world data from the Acute Coronary Syndrome Israeli Survey (ACSIS), 2000-2013. Clin. Cardiol. 2016, 40, 275-280. [CrossRef] [PubMed]

3. Schmitt, J.; Duray, G.; Gersh, B.J.; Hohnloser, S.H. Atrial fibrillation in acute myocardial infarction: A systematic review of the incidence, clinical features and prognostic implications. Eur. Heart J. 2008, 30, 1038-1045. [CrossRef] [PubMed]

4. Pedersen, O.; Bagger, H.; Køber, L.; Torp-Pedersen, C. The occurrence and prognostic significance of atrial fibrillation/-flutter following acute myocardial infarction. Eur. Heart J. 1999, 20, 748-754. [CrossRef] [PubMed]

5. Lehto, M.; Snapinn, S.; Dickstein, K.; Swedberg, K.; Nieminen, M.S. Prognostic risk of atrial fibrillation in acute myocardial infarction complicated by left ventricular dysfunction: The OPTIMAAL experience. Eur. Heart J. 2004, 26, 350-356. [CrossRef] [PubMed]

6. Soliman, E.Z.; Safford, M.M.; Muntner, P.; Khodneva, Y.; Dawood, F.Z.; Zakai, N.A.; Thacker, E.L.; Judd, S.; Howard, V.J; Howard, G.; et al. Atrial fibrillation and the risk of myocardial infarction. JAMA Intern. Med. 2014, 174, 107-114. [CrossRef]

7. Soliman, E.Z.; Lopez, F.; O’Neal, W.; Chen, L.; Bengtson, L.; Zhang, Z.-M.; Loehr, L.; Cushman, M.; Alonso, A. Atrial Fibrillation and Risk of ST-Segment-Elevation Versus Non-ST-Segment-Elevation Myocardial Infarction: The Atherosclerosis Risk in Communities (ARIC) Study. Circulation 2015, 131, 1843-1850. [CrossRef]

8. Shibata, T.; Kawakami, S.; Noguchi, T.; Tanaka, T.; Asaumi, Y.; Kanaya, T.; Nagai, T.; Nakao, K.; Fujino, M.; Nagatsuka, K.; et al Prevalence, Clinical Features, and Prognosis of Acute Myocardial Infarction Attributable to Coronary Artery Embolism. Circulation 2015, 132, 241-250. [CrossRef]

9. Laurent, G.; Zeller, M.; Dentan, G.; Moreau, D.; Laurent, Y.; Beer, J.C.; Makki, H.; Lhuillier, I.; Janin-Manificat, L.; Fraison, M.; et al. Prognostic impact of new onset atrial fibrillation in acute non-ST elevation myocardial infarction data from the RICO survey. Heart 2005, 91, 369-370. [CrossRef]

10. González-Pacheco, H.; Márquez, M.; Arias-Mendoza, A.; Álvarez-Sangabriel, A.; Eid-Lidt, G.; González-Hermosillo, A.; Azar-Manzur, F.; Altamirano-Castillo, A.; Briseño-Cruz, J.L.; García-Martínez, A.; et al. Clinical features and in-hospital mortality associated with different types of atrial fibrillation in patients with acute coronary syndrome with and without ST elevation. J. Cardiol. 2015, 66, 148-154. [CrossRef]

11. Thomsen, P.E.B.; Jons, C.; Raatikainen, M.P.; Joergensen, R.M.; Hartikainen, J.; Virtanen, V.; Boland, J.; Anttonen, O.; Gang, U.J.; Hoest, N.; et al. Long-term recording of cardiac arrhythmias with an implantable cardiac monitor in patients with reduced ejection fraction after acute myocardial infarction: The Cardiac Arrhythmias and Risk Stratification After Acute Myocardial Infarction (CARISMA) study. Circulation 2010, 122, 1258-1264. [CrossRef] [PubMed]

12. Romanov, A.; Martinek, M.; Pürerfellner, H.; Chen, S.; De Melis, M.; Grazhdankin, I.; Ponomarev, D.; Losik, D.; Strelnikov, A.; Shabanov, V.; et al. Incidence of atrial fibrillation detected by continuous rhythm monitoring after acute myocardial infarction in patients with preserved left ventricular ejection fraction: Results of the ARREST study. EP Eur. 2017, 20, 263-270. [CrossRef] [PubMed]

13. Gladstone, D.J.; Wachter, R.; Schmalstieg-Bahr, K.; Quinn, F.R.; Hummers, E.; Ivers, N.; Marsden, T.; Thornton, A.; Djuric, A.; Suerbaum, J.; et al. Screening for Atrial Fibrillation in the Older Population: A Randomized Clinical Trial. JAMA Cardiol. 2021, 6, 558. [CrossRef] [PubMed]

14. Svendsen, J.H.; Diederichsen, S.Z.; Højberg, S.; Krieger, D.W.; Graff, C.; Kronborg, C.; Olesen, M.S.; Nielsen, J.B.; Holst, A.G.; Brandes, A.; et al. Implantable loop recorder detection of atrial fibrillation to prevent stroke (The LOOP Study): A randomised controlled trial. Lancet 2021, 398, 1507-1516. [CrossRef]

15. Nielsen, F.E.; Sørensen, H.T.; Christensen, J.H.; Ravn, L.; Rasmussen, S.E. Reduced occurrence of atrial fibrillation in acute myocardial infarction treated with streptokinase. Eur. Heart J. 1991, 12, 1081-1083. [CrossRef]

16. Eldar, M.; Canetti, M.; Rotstein, Z.; Boyko, V.; Gottlieb, S.; Kaplinsky, E.; Behar, S. Significance of Paroxysmal Atrial Fibrillation Complicating Acute Myocardial Infarction in the Thrombolytic Era. Circulation 1998, 97, 965-970. [CrossRef]

17. Goldberg, R.J.; Yarzebski, J.L.; Lessard, D.M.; Wu, J.; Gore, J.M. Recent trends in the incidence rates of and death rates from atrial fibrillation complicating initial acute myocardial infarction: A community-wide perspective. Am. Heart J. 2002, 143, 519-527. [CrossRef]

18. Crenshaw, B.S.; Ward, S.R.; Granger, C.B.; Stebbins, A.L.; Topol, E.; Califf, R.M. Atrial fibrillation in the setting of acute myocardial infarction: The GUSTO-I experience. Global Utilization of Streptokinase and TPA for Occluded Coronary Arteries. J. Am. Coll. Cardiol. 1997, 30, 406-413. [CrossRef]

19. Kinjo, K.; Sato, H.; Sato, H.; Ohnishi, Y.; Hishida, E.; Nakatani, D.; Mizuno, H.; Fukunami, M.; Koretsune, Y.; Takeda, H.; et al. Prognostic significance of atrial fibrillation/atrial flutter in patients with acute myocardial infarction treated with percutaneous coronary intervention. Am. J. Cardiol. 2003, 92, 1150-1154. [CrossRef] 
20. Podolecki, T.; Lenarczyk, R.; Kowalczyk, J.; Kurek, T.; Boidol, J.; Chodor, P.; Swiatkowski, A.; Sredniawa, B.; Polonski, L.; Kalarus, Z. Effect of Type of Atrial Fibrillation on Prognosis in Acute Myocardial Infarction Treated Invasively. Am. J. Cardiol. 2012, 109, 1689-1693. [CrossRef]

21. Parashar, S.; Kella, D.; Reid, K.J.; Spertus, J.A.; Tang, F.; Langberg, J.; Vaccarino, V.; Kontos, M.C.; Lopes, R.D.; Lloyd, M.S. New-Onset Atrial Fibrillation After Acute Myocardial Infarction and Its Relation to Admission Biomarkers (from the TRIUMPH Registry). Am. J. Cardiol. 2013, 112, 1390-1395. [CrossRef] [PubMed]

22. Dorje, T.; Wang, X.; Shao, M.; Zhou, J.; Cui, X.; Zhang, F.; Qian, J.; Ge, J. Plasma N-terminal pro-brain natriuretic peptide levels predict new-onset atrial fibrillation in patients with acute myocardial infarction. Int. J. Cardiol. 2013, 168, 3135-3137. [CrossRef] [PubMed]

23. Asanin, M.; Stankovic, S.; Mrdovic, I.; Matic, D.; Savic, L.; Majkic-Singh, N.; Ostojic, M.; Vasiljevic, Z. B-type natriuretic peptide predicts new-onset atrial fibrillation in patients with ST-segment elevation myocardial infarction treated by primary percutaneous coronary intervention. Peptides 2012, 35, 74-77. [CrossRef] [PubMed]

24. Patton, K.K.; Ellinor, P.; Heckbert, S.R.; Christenson, R.H.; DeFilippi, C.; Gottdiener, J.S.; Kronmal, R.A. N-Terminal Pro-B-Type Natriuretic Peptide Is a Major Predictor of the Development of Atrial Fibrillation: The Cardiovascular Health Study. Circulation 2009, 120, 1768-1774. [CrossRef]

25. Rossi, A.; Enriquez-Sarano, M.; Burnett, J.C.; Lerman, A.; Abel, M.D.; Seward, J.B. Natriuretic peptide levels in atrial fibrillation: A prospective hormonal and Doppler-echocardiographic study. J. Am. Coll. Cardiol. 2000, 35, 1256-1262. [CrossRef]

26. Aronson, D.; Boulos, M.; Suleiman, A.; Bidoosi, S.; Agmon, Y.; Kapeliovich, M.; Beyar, R.; Markiewicz, W.; Hammerman, H.; Suleiman, M. Relation of C-Reactive Protein and New-Onset Atrial Fibrillation in Patients With Acute Myocardial Infarction. Am. J. Cardiol. 2007, 100, 753-757. [CrossRef]

27. Gal, P.; Parlak, E.; Schellings, D.A.A.M.; Beukema, R.; Berg, J.T.; Adiyaman, A.; Hof, A.W.J.V.; Elvan, A. Association of serial high sensitivity troponin $\mathrm{T}$ with onset of atrial fibrillation in ST elevation myocardial infarction patients undergoing primary percutaneous coronary intervention. Eur. Heart J. Acute Cardiovasc. Care 2015, 5, 33-42. [CrossRef]

28. Raczkowska-Golanko, M.; Raczak, G.; Gruchała, M.; Daniłowicz-Szymanowicz, L. Comprehensive Use of Routine Clinical Parameters to Identify Patients at Risk of New-Onset Atrial Fibrillation in Acute Myocardial Infarction. J. Clin. Med. 2021, 10, 3622. [CrossRef]

29. Long, B.; Long, D.A.; Tannenbaum, L.; Koyfman, A. An emergency medicine approach to troponin elevation due to causes other than occlusion myocardial infarction. Am. J. Emerg. Med. 2019, 38, 998-1006. [CrossRef]

30. Agewall, S.; Giannitsis, E.; Jernberg, T.; Katus, H. Troponin elevation in coronary vs. non-coronary disease. Eur. Heart J. 2010, 32, 404-411. [CrossRef]

31. Chuang, A.M.; Nguyen, M.T.; Kung, W.M.; Lehman, S.; Chew, D.P. High-sensitivity troponin in chronic kidney disease: Considerations in myocardial infarction and beyond. Rev. Cardiovasc. Med. 2020, 21, 191-203. [CrossRef] [PubMed]

32. Mascia, G.; Pescetelli, F.; Baldari, A.; Gatto, P.; Seitun, S.; Sartori, P.; Pieroni, M.; Calò, L.; Della Bona, R.; Porto, I. Interpretation of elevated high-sensitivity cardiac troponin I in elite soccer players previously infected by severe acute respiratory syndrome coronavirus 2. Int. J. Cardiol. 2020, 326, 248-251. [CrossRef] [PubMed]

33. Tsang, T.S.; Gersh, B.J.; Appleton, C.P.; Tajik, A.; Barnes, M.E.; Bailey, K.R.; Oh, J.K.; Leibson, C.; Montgomery, S.C.; Seward, J.B Left ventricular diastolic dysfunction as a predictor of the first diagnosed nonvalvular atrial fibrillation in 840 elderly men and women. J. Am. Coll. Cardiol. 2002, 40, 1636-1644. [CrossRef]

34. Zeng, R.-X.; Chen, M.-S.; Lian, B.-T.; Liao, P.-D.; Zhang, M.-Z. Left ventricular ejection fraction and left atrium diameter related to new-onset atrial fibrillation following acute myocardial infarction: A systematic review and meta-analysis. Oncotarget 2017, 8 , 81137-81144. [CrossRef]

35. Asanin, M.; Perunicic, J.; Mrdovic, I.; Matic, M.; Vujisic-Tesic, B.; Arandjelovic, A.; Vasiljevic, Z.; Ostojic, M. Prognostic significance of new atrial fibrillation and its relation to heart failure following acute myocardial infarction. Eur. J. Heart Fail. 2005, 7, 671-676. [CrossRef]

36. Aronson, D.; Mutlak, D.; Bahouth, F.; Bishara, R.; Hammerman, H.; Lessick, J.; Carasso, S.; Dabbah, S.; Reisner, S.; Agmon, Y. Restrictive Left Ventricular Filling Pattern and Risk of New-Onset Atrial Fibrillation After Acute Myocardial Infarction. Am. J. Cardiol. 2011, 107, 1738-1743. [CrossRef]

37. Yilmaz, R.; Demirbag, R.; Durmus, I.; Kasap, H.; Baykan, M.; Kucukosmanoglu, M.; Celik, S.; Erdol, C. Association of Stage of Left Ventricular Diastolic Dysfunction with P Wave Dispersion and Occurrence of Atrial Fibrillation after First Acute Anterior Myocardial Infarction. Ann. Noninvasive Electrocardiol. 2004, 9, 330-338. [CrossRef]

38. Pizzetti, F.; Turazza, F.M.; Franzosi, M.G.; Barlera, S.; Ledda, A.; Maggioni, A.P.; Santoro, L.; Tognoni, G. Incidence and prognostic significance of atrial fibrillation in acute myocardial infarction: The GISSI-3 data. Heart 2001, 86, 527-532. [CrossRef]

39. Rathore, S.S.; Berger, A.K.; Weinfurt, K.P.; Schulman, K.A.; Oetgen, W.J.; Gersh, B.J.; Solomon, A.J. Acute Myocardial Infarction Complicated by Atrial Fibrillation in the Elderly: Prevalence and outcomes. Circulation 2000, 101, 969-974. [CrossRef]

40. Jabre, P.; Roger, V.L.; Murad, M.H.; Chamberlain, A.M.; Prokop, L.; Adnet, F.; Jouven, X. Mortality Associated With Atrial Fibrillation in Patients With Myocardial Infarction: A systematic review and metaanalysis. Circulation 2011, 123, 1587-1593. [CrossRef] 
41. $\quad$ Lopes, R.D.; Pieper, K.S.; Horton, J.R.; Al-Khatib, S.M.; Newby, L.K.; Mehta, R.H.; Van De Werf, F.; Armstrong, P.; Mahaffey, K.W.; A Harrington, R.; et al. Short- and long-term outcomes following atrial fibrillation in patients with acute coronary syndromes with or without ST-segment elevation. Heart 2008, 94, 867-873. [CrossRef] [PubMed]

42. Congo, K.H.; Belo, A.; Carvalho, J.; Neves, D.; Guerreiro, R.; Pais, J.A.; Brás, D.; Carrington, M.; Piçarra, B.; Santos, A.R.; et al. New-Onset Atrial Fibrillation in St-Segment Elevation Myocardial Infarction: Predictors and Impact on Therapy And Mortality. Arq. Bras. Cardiol. 2019, 113, 948-957. [CrossRef] [PubMed]

43. Obayashi, Y.; Shiomi, H.; Morimoto, T.; Tamaki, Y.; Inoko, M.; Yamamoto, K.; Takeji, Y.; Tada, T.; Nagao, K.; Yamaji, K.; et al. Newly Diagnosed Atrial Fibrillation in Acute Myocardial Infarction. J. Am. Heart Assoc. 2021, 10, e021417. [CrossRef]

44. Collet, J.-P.; Thiele, H.; Barbato, E.; Barthélémy, O.; Bauersachs, J.; Bhatt, D.L.; Dendale, P.; Dorobantu, M.; Edvardsen, T.; Folliguet, T.; et al. 2020 ESC Guidelines for the management of acute coronary syndromes in patients presenting without persistent ST-segment elevation: The Task Force for the management of acute coronary syndromes in patients presenting without persistent ST-segment elevation of the European Society of Cardiology (ESC). Eur. Heart J. 2021, 42, 1289-1367. [CrossRef] [PubMed]

45. Wan, Y.; Heneghan, C.; Perera, R.; Roberts, N.; Hollowell, J.; Glasziou, P.; Bankhead, C.; Xu, Y. Anticoagulation Control and Prediction of Adverse Events in Patients with Atrial Fibrillation. Circ. Cardiovasc. Qual. Outcomes 2008, 1, 84-91. [CrossRef] [PubMed]

46. Connolly, S.J.; Ezekowitz, M.D.; Yusuf, S.; Eikelboom, J.; Oldgren, J.; Parekh, A.; Pogue, J.; Reilly, P.A.; Themeles, E.; Varrone, J.; et al. Dabigatran versus Warfarin in Patients with Atrial Fibrillation. N. Engl. J. Med. 2009, 361, 1139-1151. [CrossRef]

47. Patel, M.R.; Mahaffey, K.W.; Garg, J.; Pan, G.; Singer, D.E.; Hacke, W.; Breithardt, G.; Halperin, J.L.; Hankey, G.; Piccini, J.P.; et al Rivaroxaban versus Warfarin in Nonvalvular Atrial Fibrillation. N. Engl. J. Med. 2011, 365, 883-891. [CrossRef]

48. Granger, C.B.; Alexander, J.H.; McMurray, J.J.V.; Lopes, R.D.; Hylek, E.M.; Hanna, M.; Al-Khalidi, H.R.; Ansell, J.; Atar, D.; Ave-zum, A.; et al. Apixaban versus Warfarin in Patients with Atrial Fibrillation. N. Engl. J. Med. 2011, 365, 981-992. [CrossRef]

49. Giugliano, R.P.; Ruff, C.T.; Braunwald, E.; Murphy, S.A.; Wiviott, S.D.; Halperin, J.L.; Waldo, A.L.; Ezekowitz, M.D.; Weitz, J.I.; Špinar, J.; et al. ENGAGE AF-TIMI Investigators. Edoxaban versus Warfarin in Patients with Atrial Fibrillation. N. Engl. J. Med. 2013, 369, 2093-2104. [CrossRef]

50. Ruff, C.T.; Giugliano, R.P.; Braunwald, E.; Hoffman, E.B.; Deenadayalu, N.; Ezekowitz, M.D.; Camm, A.J.; Weitz, J.I.; Lewis, B.S.; Parkhomenko, A.; et al. Comparison of the efficacy and safety of new oral anticoagulants with warfarin in patients with atrial fibrillation: A meta-analysis of randomised trials. Lancet 2014, 383, 955-962. [CrossRef]

51. Lopes, R.D.; Heizer, G.; Aronson, R.; Vora, A.N.; Massaro, T.; Mehran, R.; Goodman, S.G.; Windecker, S.; Darius, H.; Li, J.; et al. AUGUSTUS Investigators. Antithrombotic Therapy after Acute Coronary Syndrome or PCI in Atrial Fibrillation. N. Engl. J. Med. 2019, 380, 1509-1524. [CrossRef] [PubMed]

52. Gibson, C.M.; Mehran, R.; Bode, C.; Halperin, J.; Verheugt, F.W.; Wildgoose, P.; Birmingham, M.; Ianus, J.; Burton, P.; Van Eickels, M.; et al. Prevention of Bleeding in Patients with Atrial Fibrillation Undergoing PCI. N. Engl. J. Med. 2016, 375, 2423-2434. [CrossRef] [PubMed]

53. Cannon, C.P.; Bhatt, D.L.; Oldgren, J.; Lip, G.Y.; Ellis, S.G.; Kimura, T.; Maeng, M.; Merkely, B.; Zeymer, U.; Gropper, S.; et al. REDUAL PCI Steering Committee and Investigators. Dual Antithrombotic Therapy with Dabigatran after PCI in Atrial Fibrillation. N. Engl. J. Med. 2017, 377, 1513-1524. [CrossRef] [PubMed]

54. Vranckx, P.; Valgimigli, M.; Eckardt, L.; Tijssen, J.; Lewalter, T.; Gargiulo, G.; Batushkin, V.; Campo, G.; Lysak, Z.; Vakaliuk, I.; et al. Edoxaban-based versus vitamin $\mathrm{K}$ antagonist-based antithrombotic regimen after successful coronary stenting in patients with atrial fibrillation (ENTRUST-AF PCI): A randomised, open-label, phase 3b trial. Lancet 2019, 394, 1335-1343. [CrossRef]

55. Jackson, L.R.; Ju, C.; Zettler, M.; Messenger, J.C.; Cohen, D.J.; Stone, G.W.; Baker, B.A.; Effron, M.B.; Peterson, E.D.; Wang, T.Y. Outcomes of patients with acute myocardial infarction undergoing percutaneous coronary intervention receiving an oral anticoagulant and dual antiplatelet therapy: A comparison of clopidogrel versus prasugrel from the TRANSLATE-ACS study. JACC Cardiovasc. Interv. 2015, 8, 1880-1889. [CrossRef]

56. Andreou, I.; Briasoulis, A.; Pappas, C.; Ikonomidis, I.; Alexopoulos, D. Ticagrelor Versus Clopidogrel as Part of Dual or Triple Antithrombotic Therapy: A Systematic Review and Meta-Analysis. Cardiovasc. Drugs Ther. 2018, 32, 287-294. [CrossRef] [PubMed]

57. Kirchhof, P.; Benussi, S.; Kotecha, D.; Ahlsson, A.; Atar, D.; Casadei, B.; Castella, M.; Diener, H.-C.; Heidbuchel, H.; Hendriks, J.; et al. 2016 ESC Guidelines for the management of atrial fibrillation developed in collaboration with EACTS. Eur. Heart J. 2016, 37, 2893-2962. [CrossRef]

58. Wańkowicz, P.; Staszewski, J.; Dębiec, A.; Nowakowska-Kotas, M.; Szylińska, A.; Turoń-Skrzypińska, A.; Rotter, I. Pre-Stroke Statin Therapy Improves In-Hospital Prognosis Following Acute Ischemic Stroke Associated with Well-Controlled Nonvalvular Atrial Fibrillation. J. Clin. Med. 2021, 10, 3036. [CrossRef]

59. Ibanez, B.; James, S.; Agewall, S.; Antunes, M.J.; Bucciarelli-Ducci, C.; Bueno, H.; Caforio, A.L.P.; Crea, F.; Goudevenos, J.A.; Halvorsen, S.; et al. 2017 ESC Guidelines for the management of acute myocardial infarction in patients presenting with STsegment elevation: The Task Force for the management of acute myocardial infarction in patients presenting with ST-segment elevation of the European Society of Cardiology (ESC). Eur. Heart J. 2018, 39, 119-177. [CrossRef] 
60. Groenveld, H.F.; Crijns, H.J.; Berg, M.V.D.; Van Sonderen, E.; Alings, A.M.; Tijssen, J.G.; Hillege, H.L.; Tuininga, Y.; Van Veldhuisen, D.J.; Ranchor, A.V.; et al. The Effect of Rate Control on Quality of Life in Patients With Permanent Atrial Fibrillation: Data From the RACE II (Rate Control Efficacy in Permanent Atrial Fibrillation II) Study. J. Am. Coll. Cardiol. 2011, 58, 1795-1803. [CrossRef]

61. Fosbøl, E.L.; Seibæk, M.; Brendorp, B.; Moller, D.V.; Thune, J.J.; Gislason, G.H.; Torp-Pedersen, C.; Køber, L. Long-term prognostic importance of resting heart rate in patients with left ventricular dysfunction in connection with either heart failure or myocardial infarction: The DIAMOND study. Int. J. Cardiol. 2010, 140, 279-286. [CrossRef] [PubMed]

62. Steg, P.G.; James, S.K.; Atar, D.; Badano, L.P.; Lundqvist, C.B.; Borger, M.A.; Di Mario, C.; Dickstein, K.; Ducrocq, G.; FernandezAviles, F.; et al. ESC Guidelines for the management of acute myocardial infarction in patients presenting with ST-segment elevation: The Task Force on the management of ST-segment elevation acute myocardial infarction of the European Society of Cardiology (ESC). Eur. Heart J. 2012, 33, 2569-2619. [CrossRef] [PubMed]

63. Um, K.J.; McIntyre, W.F.; Healey, J.S.; Mendoza, P.A.; Koziarz, A.; Amit, G.; Chu, V.A.; Whitlock, R.P.; Belley-Côté, E.P. Pre- and post-treatment with amiodarone for elective electrical cardioversion of atrial fibrillation: A systematic review and meta-analysis. EP Eur. 2019, 21, 856-863. [CrossRef]

64. Schmidt, A.S.; Lauridsen, K.G.; Torp, P.; Bach, L.F.; Rickers, H.; Løfgren, B. Maximum-fixed energy shocks for cardioverting atrial fibrillation. Eur. Heart J. 2020, 41, 626-631. [CrossRef] [PubMed]

65. Furniss, S.S.; Sneyd, J. Safe sedation in modern cardiological practice. Heart 2015, 101, 1526-1530. [CrossRef] [PubMed]

66. Potpara, T.S.; Mujovic, N.; Proietti, M.; Dagres, N.; Hindricks, G.; Collet, J.-P.; Valgimigli, M.; Heidbuchel, H.; Lip, G.Y.H. Revisiting the effects of omitting aspirin in combined antithrombotic therapies for atrial fibrillation and acute coronary syndromes or percutaneous coronary interventions: Meta-analysis of pooled data from the PIONEER AF-PCI, RE-DUAL PCI, and AUGUSTUS trials. EP Eur. 2019, 22, 33-46. [CrossRef]

67. Gargiulo, G.; Goette, A.; Tijssen, J.; Eckardt, L.; Lewalter, T.; Vranckx, P.; Valgimigli, M. Safety and efficacy outcomes of double vs. triple antithrombotic therapy in patients with atrial fibrillation following percutaneous coronary intervention: A systematic review and meta-analysis of non-vitamin K antagonist oral anticoagulant-based randomized clinical trials. Eur. Heart J. 2019, 40, 3757-3767. [CrossRef]

68. Chao, T.-F.; Lin, Y.-J.; Chang, S.-L.; Lo, L.-W.; Hu, Y.-F.; Tuan, T.-C.; Liao, J.-N.; Chung, F.-P.; Chen, T.-J.; Lip, G.Y.H.; et al. Incident Risk Factors and Major Bleeding in Patients with Atrial Fibrillation Treated with Oral Anticoagulants: A Comparison of Baseline, Follow-up and Delta HAS-BLED Scores with an Approach Focused on Modifiable Bleeding Risk Factors. Thromb. Haemost. 2018, 47, 768-777. [CrossRef]

69. Guo, Y.; Lane, D.A.; Chen, Y.; Lip, G.Y.; mAF-App II Trial Investigators. Regular Bleeding Risk Assessment Associated with Reduction in Bleeding Outcomes: The mAFA-II Randomized Trial. Am. J. Med. 2020, 133, 1195-1202.e2. [CrossRef] 